\title{
ITINERARIOS DE UN ARCHIVISTA EN REBELIÓN: LA CRÓNICA DE LA LITERATURA Y EL TALLER DE LA PRENSA DE JESÚS SANOJA HERNÁNDEZ (VENEZUELA, 1930-2007)
}

\author{
POR \\ Camila Pulgar Machado \\ Universidad Central de Venezuela
}

Estas breves páginas se proponen explicar la indagatoria que me ocupa en este momento. Mi estadía en el Departamento de Lenguas y Literaturas Hispánicas de la Universidad de Pittsburgh, bajo el patrocinio de la beca Fulbright para profesores universitarios, tiene el propósito de actualizar y continuar mi investigación en torno al archivo cultural del gran periodista, historiador e intelectual venezolano Jesús Sanoja Hernández (Tumeremo, 1930-Caracas, 2007). Primeramente, debo dar las gracias a los profesores Dan Balderston, John Beverley y Juan Duchesne por el apoyo recibido y la consideración que me han brindado.

Quizá, antes de ingresar en la presentación de quién fue Jesús Sanoja Hernández, debo decirles que el estudio del archivo o desorden de papeles de este intelectual venezolano, ocupa mi trabajo no sólo como investigadora sino como docente en la Escuela de Letras de la Universidad Central de Venezuela en la que enseño desde hace 15 años. Allí, junto con un grupo de 24 pasantes académicos y algunos colegas, creé un proyecto docente investigativo y de edición titulado La imagen poética de Caracas: rescate historiográfico de Jesús Sanoja Hernández. Este proyecto basado en el rescate y, sobre todo, la actualización de un archivo, proyecto de investigación semielaborado que dejó Sanoja, sobre la imagen de Caracas en poemas publicados en prensa, principalmente, desde 1890 hasta 1965. Escuchando sus palabras, él trabajaba de acuerdo a "los diversos aspectos de Caracas": "calles, templos, paseos, ríos, quebradas, puentes, montañas, lluvias, atmósfera, crepúsculo, alba, clima, pájaros, etc., es decir, que se examine al mismo tiempo los elementos orográficos, hidrológicos, climatológicos y otros a los cuales cantó el espíritu de los poetas". ${ }^{1}$

\footnotetext{
1 Sanoja responde a una entrevista de 1967 publicada en el diario venezolano El Nacional. Este es un recorte de prensa que guardó Sanoja en su casa y nos facilitó su esposa María Eugenia Villalba pero debemos ahora buscar sus datos completos en El Nacional, pues al cortarlo se suprimió cierta información. Creemos que se fecha 25 de febrero de 1967, se titula "100 obras poéticas sobre Caracas, Investiga el Profesor Jesús Sanoja Hernández".
} 
Igualmente, este proyecto que creció según un orden de carencias pues en su momento no tuvo un equipo editor y quedó, como él mismo escribió en sus curricula de los setentas, "semielaborado", tuvo un destino, así como el Libro de los pasajes de Walter Benjamin, disperso. No obstante, hoy día hay este equipo de profesores y estudiantes de la Facultad de Humanidades y Educación que, gracias al aporte de la familia Sanoja Villalba, ha podido formular una propuesta para curar e interpretar estos papeles a luz de las investigaciones actuales sobre el archivo, sobre la misma iniciativa benjaminiana, sobre el coleccionismo y el tejido documental. Si bien no podemos precisar, como lo hace Rolf Tiedemann en la "Introducción del editor" al Libro de los pasajes de Walter Benjamin, cuáles son las teorías o los textos teóricos que acompañaron a Sanoja, ${ }^{2}$ de su parte no hubo esa apuesta benjaminiana por la formulación filosófica, el proyecto, el "Estudio de Caracas" posee en sus legajos una fuerza impresionante y un tipo de reflexión sobre los materiales y la materia misma que posibilita el paralelismo.

También Sanoja, como Benjamin, va a mirar el crecimiento urbano de un siglo, principalmente el XX; va a dedicar páginas a "Urbanismo y arquitectura", papeles alternos a los poemas sobre Caracas que componen este archivo: estamos en un suerte de rítmica segmentada entre las reflexiones y las imágenes y ambas instancias también se entremezclan produciéndose un tercer tipo de texto, texto-ficha, donde los apuntes del investigador aparecen muy formalmente en el margen de la página del poema: páginas sofisticadas. Páginas con las que cualquier investigador, profesor de la literatura venezolana podría trabajar en el aula. Hay un didactismo elevado o resueltamente elaborado que presenta las concreciones de esta intención omniabarcante de Sanoja - pero de naturaleza inconclusa- en torno a la construcción de la ciudad de Caracas. Leo al auror:

[...]. En nuestra década [los sesenta] el poeta fundamenta, por lo general, su visión en percepciones entrelazadas donde lo acústico, lo oliente, lo fisiológico, lo erótico, lo puramente objetal se impregnan de una nueva religiosidad. Hay sí una preferencia por la exterioridad media y tipificante, gruesa que reside necesariamente en la ciudad de las vitrinas (punto de convergencia de todas las clases sociales), de la multitud callejera y de lo publicitario y consuntivo. ${ }^{3}$

En el caso de Benjamin, Tiedemann menciona La obra de arte de la época de su reproductibilidad técnica, los textos dedicados a Baudelaire y Sobre el concepto de la historia (Libro de los pasajes 10).

3 Estos papeles inéditos pertenecen hoy al archivo del proyecto: "La imagen poética de Caracas: Rescate historiográfico de Jesús Sanoja Hernández", se trata de un proyecto de grupo adscrito al Instituto de Investigaciones Literarias, subsidiado por el Consejo de Desarrollo Científico y Humanístico de la UCV (año 2011). Dirijo el proyecto junto con los profesores María Eugenia Martínez, directora del Instituto, y Ángel Gustavo Infante.

Revista Iberoamericana, Vol. LXXXII, Núm. 254, Enero-Marzo 2016, 173-184 ISSN 0034-9631 (Impreso)

ISSN 2154-4794 (Electrónico) 
Son observaciones de Sanoja que van en dirección a una historiografía; no obstante, interrumpida en sus generalizaciones por la insurgencia de datos, de acumulaciones repentinas, que modifican la dirección didáctica hacia un modo rapsódico, de “ensambley móvil textual", "especie de rompecabezas donde las piezas se mueven a gusto y capricho del autor", 4 y cuya magnitud, cuya cantidad abre una espacialidad deconstructiva, tal vez, muy paradójica.

Es decir, el proyecto está compuesto por legajos diversificadores de la materia: la carpeta de los ríos, la carpeta del motivo de los obreros, la carpeta de la imagen del Ávila, de la situación del destierro, del asunto de la mujer, del carnaval, de la pintura. Y luego, la importantísima carpeta de las cárceles:

-Y como cuestión relativamente nueva -agrega Sanoja Hernández- se incorpora la poesía hecha en La Rotunda, que es muy abundante, en Guasina y diversas cárceles del país en diferentes épocas $[\ldots]$

-Si algo original pudiera arrojar este estudio -clarifica Sanoja en 1967- es la presencia de poemas y poetas totalmente desconocidos, al lado de los tradicionalmente famosos y sistemáticamente tratados en la literatura nacional. ${ }^{5}$

Sanoja construye con una energía notable una "lista preliminar de poetas venezolanos" $"$ de más de 500 nombres y el proyecto, que hemos llamado La imagen poética de Caracas: rescate historiográfico de Jesús Sanoja Hernández, alberga esta reproducción de nombres y poemas respectivos, que en alguna carpeta aparecen desde la a 'a' hasta la 'e' estableciéndose entonces la intención de una antología que incluyera "el amplio material perdido en las páginas de revistas y periódicos”, tal como agrega en la entrevista.

En fin, debemos partir apuntando que no estamos ante un literato puro, que este autor fue un periodista de amplio alcance; pues, a pesar de su parquedad acostumbrada, contó con un público lector de número considerable. Público asiduo a sus análisis políticos, a sus comentarios en torno a la historia contemporánea, a sus datos siempre envueltos en la singularidad de un punto de vista que aunque partícipe del sentido común, de la opinión pública, cautivó por su carácter excepcional y, tantas veces, genial. En Venezuela muchos recuerdan la memoria de Sanoja como una fuente privilegiada de conocimientos que, tantas veces, habían sido borrados por ese olvido general del tiempo habitual que registra $\mathrm{y}$, asimismo, despacha la prensa; espesor saturado de acontecimientos que al día siguiente pasan a segundo plano y allí descienden hasta la

4 Palabras de Sanoja que definen el estilo de Rufino Blanco ("Blanco Fombona y el país sin memoria" xxxv).

5 En el artículo mencionado: "100 obras poéticas sobre Caracas, Investiga el Profesor Jesús Sanoja Hernández".

6 Material inédito, titulado "Lista preliminar de poetas venezolanos".

Revista Iberoamericana, Vol. LXXXII, Núm. 254, Enero-Marzo 2016, 173-184 ISSN 0034-9631 (Impreso)

ISSN 2154-4794 (Electrónico) 
desmemoria. En tales predios polvorientos y ruinosos, en esa oscuridad de la historia hemerográfica de una nación, Sanoja se desplazaba como un artífice de la crónica; es decir, iba, diariamente, articulando breves textos lúcidos sobre el tiempo de la polis que está en acción o en conexión con un registro pasado. Su mayor pasión estuvo, tal vez, en esa articulación que alimentó su análisis, en ese puente entre el archivo y la percepción de acento personal, la apreciación subjetiva que sabía canalizar el mar sin fondo de periódicos muertos. Allí, además de la política, estuvo depositada su devoción clarividente por ciertas aristas literarias.

Así, nuestra inquietud: cómo referir la literatura en el archivo de Sanoja Hernández, desplaza de inmediato la importancia crucial que hubiéramos podido darle a su único y tan referido poemario La mágica enfermedad (primera edición 1969, segunda acompañada de poemas escritos entre 1967 y 1993 y publicada por Monte Ávila), privilegiando entonces aquí su afición por la producción periodística y archivísitca de corte literario.

De hecho, buscamos indicar el contraste existente entre esta experiencia imaginaria contenida en La mágica enfermedad (asimismo, en los varios poemas escritos al margen de este libro, en fin, en el hábito de hacer poesía) y la producción mayoritaria de crónicas literarias, o sea, muy por encima del impulso poético de este intelectual. Luis Alberto Crespo recuerda las palabras de Ángel Rosenblat: "Cuídese del periodismo, Sanoja”. Y en general, respecto a Sanoja poeta ha prevalecido una suerte de clamor o por lo que no escribió o no publicó; una interrogación por el hecho de haber escrito un sólo poemario, si acaso se debió a un "ninguneo" de parte del mundo literario venezolano como se pregunta Gonzalo Ramírez en "Jesús Sanoja Hernández: primero que nada, poeta".

Y si bien no es momento para abordar el tejido de las mágicas imágenes, de ese paisaje anímico, de su existencialismo poético, sí pensamos que Sanoja estuvo dominado por el estímulo que encontró, más que en el símbolo y la inspiración lírica, en la creación incesante de alegorías hemerográficas: las crónicas literarias. Pues también nos queda meditar un poco más a fondo, imaginar mejor a este literato que como indica Luis Alberto Crespo en otro escrito, obedecía a sus pasiones; quizá entonces no tan enamorado del acto de hacer poesía. Si comparáramos tendríamos que admitir que en Sanoja Hernández prevaleció la pasión por el archivo, clandestino además, y la necesidad de referir lo histórico, lo político, de hacer historiografía "arbitraria", promovida, en todo caso, por el libre albedrío del ensayista y el ejercicio diario de la opinión pública. Así como al poeta, Sanoja también aisló de sí al metodólogo puro, apoyándose más bien en los artificios de una memoria que, aunque personal, fue providencial. Lo que produjo una admiración hacia él compleja, pues aun siendo un hombre modesto, conoció el prestigio pero nunca sin salvarse del reclamo reticente de su público coetáneo, de muchos de sus compañeros de generación. Se le reclamó o por falta a la poesía, o si no, por ejercitarse en una historiografía demasiado ensayística para hacer "verdad".

La mención a su generación es crucial, este intelectual que ya pudiéramos estudiar como a un autor de "literatura menor", haciendo uso de las conceptualizaciones de

Revista Iberoamericana, Vol. LXXXII, Núm. 254, Enero-Marzo 2016, 173-184 ISSN 0034-9631 (Impreso)

ISSN 2154-4794 (Electrónico) 
Deleuze y Guattari y rejuveneciendo así a Sanoja, revitalizando ese almacén de antigüedades que fue el archivo, su carga más pesada, funcionó, desde el inicio de su trayectoria, dando respuesta a su generación, a un colectivo. La literatura aquí, dirían Deleuze y Guattari, no es cuestión de genio individual, sino "es la que produce una solidaridad activa, a pesar del escepticismo" (30) que pueda albergar su demiurgo. Aún la relación entrañable que Jesús Sanoja alimentaría con los inicios del siglo XX, con la remembranza y los datos de un corpus integrado por autores venezolanos como Antonio Arráiz, José Rafael Pocaterra, Salustio González Rincones, José Antonio Ramos Sucre y siempre más, su mayor interés estuvo en el relato permanente del itinerario de sus contemporáneos. ¿Cuántos prólogos, notas, crónicas escribió en homenaje fraternal? Cuando leemos su trilogía póstumamente publicada y uno de sus únicos libros: Entre golpes y revoluciones, palpamos (desde el primer volumen que inicia con la historia familiar) esta seducción hacia el espectro generacional que se va imponiendo en el relato, ocultando la referencia personal, el móvil de la intención autobiográfica, que deja de ser prioritario o se diluye en límites más amplios. O en todo caso, el proyecto creador de Sanoja Hernández no fue individualista, esto nos parece decisivo para entender su desprendimiento final de la poesía.

Decimos 'final' pues la creación poética de Sanoja estuvo concentrada en las décadas del 50 y el 60, principalmente. Escasa poesía escribió del 70 en adelante. Estos años, sobre todo subrayamos del 58 al 68, fueron de una notable productividad intelectual que sorprende por sus múltiples intereses, por la versatilidad de sus actuaciones y, asimismo, la profundidad que adquieren bajo su pluma exigente, que aun apuntando a géneros breves del discurso, socava el fondo de una conciencia nacional. De esa adolescencia que llama "Revelaciones" y que simbólicamente comienza cuando el joven de 14 años ve "por primera vez el paisaje imaginado: Caracas" (25), Sanoja Hernández pasa, de inmediato, a construir un entramado de revistas, periódicos, libros, hechos políticos, personajes de relieve entre los que deslizará sus opiniones, observaciones (y no tesis) sobre la historia política contemporánea del país. Así se construye el relato de Entre golpes y revoluciones, practicando una suerte de miscelánea escrituraria, de prosa rapsódica que logra la coherencia en el hilo conductor del gran comentario. Observador, comentarista, columnista de Válvula, Tribuna Popular, El Nacional, Gaceta Estudiantil, Noticias de Venezuela y Al día en México, Principios en Chile, Élite, La Esfera, El Mundo, El Independiente, El Pregón, La Razón, Cruz del Sur, Tabla Redonda, En letra roja, etc., allí Sanoja va ejercitando una rítmica de trabajo que reflejará, a pesar de la cantidad desbordante, una concentración estilística. Hablamos de su personalidad en el texto. Sus columnas se sostuvieron en la perseverancia del escritor de a diario y, asimismo, en la construcción de seudónimos y de un fraseo de hondura literaria, ensayística que lo distinguió del resto. No todo periodista logra el sello de la firma. Sanoja Hernández utilizó cerca de 10 seudónimos y sin embargo su estilo fue inconfundible. ¿Su estilo literario acaso?

Revista Iberoamericana, Vol. LXXXII, Núm. 254, Enero-Marzo 2016, $173-184$ ISSN 0034-9631 (Impreso)

ISSN 2154-4794 (Electrónico) 
Recordemos que después de su destierro en México, entre 1952 y 1956, de haber cursado años de economía y haber sido preso antes, en el 49, 50, 51 y 52; de haber sido columnista fijo en el periódico comunista Tribuna Popular entre 1949-50, dirige uno de los grupos principales de la vanguardia literaria venezolana: Tabla Redonda, junto al poeta Rafael Cadenas y el historiador Manuel Caballero. Es decir, durante los años 59 al 65, tan cargados vital e intelectualmente, pisa adelante con el ímpetu del líder. Basta mencionar el papel mediador que protagonizó en lo que él mismo llamó 1958: año estelar del movimiento estudiantil, cuando fue el encargado estudiantil de recibir a Nixon en su acontecida visita a Venezuela, que el mismo Nixon narraría años después en unas memorias. Durante ese año fue presidente del Centro de Estudiantes de Humanidades, vicepresidente electo y presidente encargado de la Federación de Centros Universitarios de la Universidad Central de Venezuela, en ese año también se inició como secretario de la Fracción Parlamentaria del Partido Comunista de Venezuela. En fin, estamos en el umbral de una trayectoria que así como despegaría con la fuerza de la política democrática, se adentraría más reposada o meditativa en los subterfugios de la memoria nacional. Desarrollándose en este autor un doble impulso: la respuesta política inmediata, bajo el ritmo acelerado de la prensa; y, al mismo tiempo, la investigación sostenida desde una mirada privilegiada no sólo por los materiales consultados sino por la capacidad de observación de la literatura en su ámbito cultural, en su devenir histórico y sus extraños vínculos políticos con la realidad.

Sin proponer jamás una tesis al respecto, sin llegar al punto de un desarrollo teórico literario, su maestría en la crónica lo llevaría a organizar ciertas apreciaciones sobre nuestra literatura cuya frecuencia de aparición indican más que una pasión: un oficio real.

Esta investigación se propone entonces el estudio de la relación entre Jesús Sanoja Hernández y su archivo literario.

El archivo, el depósito que generó el afán acumulador, el coleccionismo de literatura vernácula (despreciada frecuentemente por la élite culta, estética, a veces despolitizada de la Venezuela democrática) ocupó el tiempo y el espacio de esta mente superdotada. Allí, en su reino de papeles en reproducción indetenible, albergó todos los folletos y las publicaciones clandestinas de la izquierda venezolana, pero además, lo hizo en función de una interpretación procesadora de los materiales. Sin máquina computadora, sin las estrategias tecnológicas de la actualidad, se enfrentó a un espesor que crecía a propósito del ejercicio crítico de su día a día. De diario existir, Sanoja sin embargo estaba albergando en su propia casa una saturación.

Esta complejidad entre la productividad del hermeneuta y la acumulación asfixiante de papeles desperdigados, por lo pronto, para nosotros implica una metáfora para entender la memoria y la relación con la historia. La problemática acaparó al autor, desdibujó las delimitaciones subjetivas y lanzó a su propio demiurgo hacia el horror vacui de este infinito número de materiales archivándose. Como indica Foucault en La arqueología del saber, el archivo está compuesto de "obras diferentes", "libros

Revista Iberoamericana, Vol. LXXXII, Núm. 254, Enero-Marzo 2016, 173-184 ISSN 0034-9631 (Impreso)

ISSN 2154-4794 (Electrónico) 
dispersos", "toda esa masa de textos" "y tantos autores que se conocen y se invalidan los unos a los otros, se despojan, coinciden, sin saberlo y entrecruzando obstinadamente sus discursos singulares en una trama de la que no son dueños, cuya totalidad no perciben y cuya amplitud miden mal" (215).

Entonces y para concluir, ¿cómo queda, cómo ver, cómo comprender a la luz de ese archivo de la opinión pública y la prensa que construyó Sanoja entre, de un lado, la "impaciencia" del lector operante (Benjamin, "El autor como productor" 121) ante el diario discurrir de la noticia política; y del otro, sus "intervenciones empíricas", más que teóricas, en el subsuelo de las tradiciones literarias modernas, ¿cómo queda, cómo se lee esa relación con la literatura?

¿Cómo entenderlo también en comparación con otros paradigmas, con otras búsquedas documentales, es decir, otros archivos o saberes de la intelectualidad latinoamericana? Ya que como vimos con Foucault el archivo es el resultado de una verdadera contienda de saberes, incluyendo el desperdicio, los restos inútiles que dejan las guerras.

Julio Ramos habla de la conformación, desde Martí en particular, de una "biblioteca alternativa" negando "el modelo de la importación" de libros, de bibliotecas extranjeras que había prevalecido hasta entonces. Martí impone, con la incisión de su mirada, la tarea de construcción del "archivo de la tradición, un saber alternativo y americano" (Desencuentros 400). ¿Qué proyección latinoamericanista tendría el archivo de Sanoja radicalmente vernáculo? ¿Qué diferencias y similitudes hallaríamos al comparar la búsqueda hemerobibliográfica de Sanoja con la de Angel Rama, más libresca, considerando el paso de este último por Caracas, incluso percibiendo el aprecio mutuo entre ambos intelectuales, la participación de Sanoja en volúmenes claves de la Biblioteca Ayacucho, dirigida por Rama? Considerando además lo que John Beverley subraya al analizar las intenciones utópicas de Rama, de su apuesta por la "transculturación", por el mestizaje finalmente, como una "teleología, no sin marcas de violencias y pérdidas", "pero necesaria en última instancia para la formación del Estado-moderno y de una identidad nacional (o continental) que sería distinta a la suma de sus partes" (78).

¿Qué dice el archivo de Sanoja al respecto? ¿Cómo se maneja, cómo se interpreta según el trascendente concepto de ciudad letrada y la sobrevaloración ideológica que, tal como ve Beverley, hace la izquierda latinoamericana de la literatura como esa instancia capaz de sintetizar, modelar la identidad? Sobre todo hoy a la luz de los cuestionamientos que dicha estimación ya ha recibido (82-83). Beverley explica:

Lo que ha socavado la hegemonía de la "ciudad letrada" y la efectividad de la "transculturación narrativa" de Rama en tanto forma de modernización cultural ha sido la mutación de la esfera pública latinoamericana causada por el tremendo crecimiento, en los últimos treinta y cuarenta años, de los medios audiovisuales masivos. El gran crítico brasileño Antonio Cándido observó, desesperadamente, en su seminal ensayo

Revista Iberoamericana, Vol. LXXXII, Núm. 254, Enero-Marzo 2016, 173-184 
sobre literatura y subdesarrollo, que el auge de los medios masivos implicaba una renovada postergación de la cultura literaria como modelo o práctica formativa para una ciudadanía educada [...]. (82)

Y allí vemos una de las razones de esa distancia que va generándose entre Sanoja y la literatura a medida que se entrega pulsionalmente a la exigencia voraz de ese auge masivo de la comunicación social, de la prensa. En la medida en que se decide no por la cultura letrada o literaria, y menos por el academicismo, sino abiertamente por el desarrollo de la opinión pública, de la opinión política en y sobre Venezuela.

\section{Obras citadas de Sanoja Hernández \\ (LIBROS, PRÓLOGOS, FOLLETOS)}

Sanoja Hernández, Jesús. Diccionario de terrorismo. Caracas: Los Libros de El Nacional, 2002.

Entre golpes y revoluciones. Tomo I. Caracas: Debate, 2007.

La mágica enfermedad. Caracas: Monte Ávila Editores, 1997.

La universidad: ¿culpable o víctima? Caracas: Fondo Editorial Venezolano, 1967. Prólogo. Memorias de un venezolano de la decadencia. José Rafael Pocaterra.

Tomo I. Bibliografía de Roberto Lovera de Sola. Tomo 1. Caracas: Biblioteca Ayacucho, 1990.

Prólogox. Antología poética. Salustio González Rincones. Caracas: Monte Ávila, 1977.

"Rufino Blanco Fombona y el país sin memoria". Ensayos históricos. Rulfino

Blanco Fombona. Selección y cronología de Rafael Ramón Castellanos. Caracas: Biblioteca Ayacucho, 1981.

"Una década de luchas universitarias (1948-1958)". Trabajo para optar a Asistente, Caracas: FHE-Universidad Central de Venezuela, 1971.

\section{BiBLIOGRAFÍA}

Benjamin, Walter. Discursos interrumpidos I. Filosofía del arte y de la historia. Jesús Aguirre, trad. Madrid: Taurus, 1972.

"El autor como productor". Tentativas sobre Brecht (Iluminaciones III). 1934.

Jesús Aguirre, trad. Madrid: Taurus, 1974.

"El Surrealismo: la última instantánea de la inteligencia Europea". Imaginación

$y$ sociedad. Jesús Aguirre, trad. Madrid: Taurus, 1998.

Libro de los pasajes. Rolf Tiedemann, ed. Madrid: Akal Ediciones, 2005.

Revista Iberoamericana, Vol. LXXXII, Núm. 254, Enero-Marzo 2016, 173-184 
El origen del 'Trauerspiel' alemán. Obras. Libro I, vol. 1. Rolf Tiedemann y Hermann Schweppenhäuser, eds. Madrid: Abada Editores, 2007.

Beverley, John. "Transculturación y subalternidad: las afueras de la ciudad letrada". Subalternidad y representación. Madrid: Iberoamericana, 2004.

Bordieu, Pierre. "Campo intelectual y proyecto creador". Problemas del estructuralismo. 1966. México: Siglo XXI, 1967.

Bürger, Peter. Teoría de la vanguardia. 1974. Jorge García, trad. Barcelona: Ediciones Península, 1997.

Crespo, Luis Alberto. Prólogo. La mágica enfermedad. Jesús Sanoja Hernández. Caracas: Monte Ávila, 1997.

“La pasión de Jesús Sanoja Hernández". El Universal. 14 oct. 1990: 4-5.

Deleuze y Guattari. Kafka. Por una literatura menor. 1975. Versión de Jorge Aguilar Mora. México: Era, 1998.

"Rizoma”. Mil mesetas. Capitalismo y esquizofrenia. 1980. José Vázquez, trad. Valencia: Pre-textos, 2000.

Derrida, Jacques. Mal de archivo. Una impresión freudiana. Paco Vidarte, trad. Madrid: Trotta, 1997

Foucault, Michael. The Order of Things: An Archaeology of the Human Sciences. New York: Vintage Books, 1973.

"El a priori histórico y el archivo". La arqueología del saber. 1969. Aurelio Garzón del Camino, trad. México: Siglo XXI, 1999.

González Echevarría, Roberto. Mito y archivo. Una teoría de la narrativa latinoamericana. México: Fondo de Cultura Económica, 2000.

Guattari, Felix y Suely Rolnik. Micropolitica. Cartografías del deseo. 2005. Florencia Gómez, trad. Madrid: Traficantes de sueños, 2006.

Habermas, Jürgen. Historia y crítica de la opinión pública. 1962. Antonio Doménech y Francisco Javier Gil Martín, trads. Barcelona: GG Massmedia, 1999.

Rama, Ángel. Prólogo y selección. Antología de El Techo de la Ballena. Caracas: Fundarte, 1987.

Ramírez, Gonzalo. “Jesús Sanoja Hernández: primero que nada, poeta”. Día-crítica 2 (2007): 52-53.

Ramos, Julio. Desencuentros de la modernidad en América Latina: literatura y política en el siglo XIX. 1989. Caracas: El perro y La Rana, 2009.

Williams, Raymond. "La política de la vanguardia". La política del modernismo. Contra los nuevos conformistas. 1989. Compilación e introducción de Tony Pinkney. Buenos Aires: Ediciones Manantial, 1997. 


\section{BiBLIOGRAFÍA COMPLEMENTARIA}

Appadurai, Arjun. "Archive and Aspiration". Information Is Alive: Art and Theory on Archiving and Retrieving Data. Joke Brouwer y Aejen Mulder, eds. Rotterdam: V2 Publishing/nai Publisher, 2003.

Chakrabarty, Dipesh. Provincializing Europe: Postcolonial Thought and Historical Difference. Princeton: Princeton UP, 2000.

Foster, Hal. "An Archival Impulse." October 110 (2004): 3-22.

Rancière, Jacques. El espectador emancipado. Ariel Dilon, trad. Buenos Aires: Manantial, 2011.

Sekula, Allan. "The Body and the Archive." October 39 (1986): 3-64..

Spieker, Sven. The Big Archive. Art from Bureaucracy. Cambridge: The MIT P, 2008.

Agradecimientos a la Escuela de Letras y el Instituto de Investigaciones Literarias (Universidad Central de Venezuela) en el archivo de Jesús Sanoja Hernández (Tumeremo, 1930 / Caracas, 2007).

Participantes graduados (licenciados) del Proyecto, título del Informe de pasantía académica y fecha de presentación:

\section{Del proyecto la Imagen poÉtica de Caracas}

Samantha Sassi, La poesía de Caracas. Rescate historiográfico de Jesús Sanoja Hernández (noviembre, 2011).

Erika Hernández Lehmann, La imagen poética de Caracas: rescate historiográfico de Jesús Sanoja Hernández (11 enero 2012).

Ana Antelo, La ciudad de Caracas: historiografia y fragmentos de Jesús Sanoja Hernández (11 diciembre 2012).

Mayra Salazar, La imagen de Caracas, rescate historiográfico (diciembre, 2012).

Marialex Espinoza, Caracas de poesía: rescate historiográfico de la imagen poética de Caracas según Jesús Sanoja Hernández (10 diciembre 2012).

Laura Rosales, La poesía carcelaria en la ciudad de Caracas. Rescate historiográfico de Jesús Sanoja Hernández (15 julio 2013).

Iván Corona, Rescate historiográfico de la imagen poética de Caracas (8 enero 2013).

Joana Ribeiro, La ciudad y sus archivos según Sanoja Hernández (17 mayo 2013).

Criscar Mundaray, La experiencia del habitante de la ciudad de Caracas. La poesía como archivo de crónica (29 julio 2013).

Nagdy Guevara, Jesús Sanoja Hernández: rescate historiográfico de la poética de Caracas (23 enero 2014).

Revista Iberoamericana, Vol. LXXXII, Núm. 254, Enero-Marzo 2016, 173-184 ISSN 0034-9631 (Impreso)

ISSN 2154-4794 (Electrónico) 
Geraldine Gutiérrez, Edición del Libro para el Proyecto de Investigación "La imagen poética de Caracas: Rescate Historiográfico de Jesús Sanoja Hernández”. En proceso.

II. UNIVERSIDAD

Osmar Peña, Edición digital del libro "Una década de luchas universitarias 19481958" (1971) (junio, 2013).

Clara Guedez, Corrección y edición de "Una década de luchas universitarias 19481958" (1971). En proceso.

Sasha Di Ventura, Edición digital de "La universidad: ¿culpable o víctima?” (1967). En proceso.

III. Revista CULTURAl TABLA REDONDA (1959-1965)

María Karina de Gouveia, En torno a la obra hemerográfica de Jesús Sanoja Hernández: reedición de la revista cultural Tabla Redonda (1959-1965) (julio, 2013).

Oswaldo Florex, Conservación y reedición de la revista cultural Tabla Redonda (1959-1965). En proceso.

IV. CRÓNICAS Y ENSAYos CULTURALES (1958 a 1990)

Winder Ortiz, Jesús Sanoja Hernández: entre el archivo y las crónicas (18 diciembre 2013).

Karem Iglesias, Caracas y lo momentáneo: panorámica ensayística de Jesús Sanoja Hernández (febrero, 2014).

Daniela Olivero, Jesús Sanoja Hernández: la libertad en la palabra escrita (24 marzo 2014).

Pedro Ignacio Muñoz, Saberes imposibles: improbabilidades ensayísticas en torno a Jesús Sanoja Hernández (marzo, 2014).

Cindy Barreto, Edición de las crónicas de Jesús Sanoja Hernández: un Ulises de ciudad y de web (29 julio 2014).

V. PoEsía (1958-199?)

Nayelí Rojas, La poesía de Jesús Sanoja Hernández. En proceso.

Revista Iberoamericana, Vol. LXXXII, Núm. 254, Enero-Marzo 2016, 173-184 ISSN 0034-9631 (Impreso)

ISSN 2154-4794 (Electrónico) 
VI. PÁgina Web

Leonardo Ángulo, La imagen poética de Caracas: rescate de la obra de Jesús Sanoja Hernández en la web (julio, 2014).

Sofía Salazar, La imagen poética de Caracas (web). En proceso. 